\title{
Hsp90 Structure and Function in Cancer
}

\author{
Nassim Faridi (iD ${ }^{1,{ }^{*}}$ and Arezou Ghahghaei ${ }^{2,{ }^{* *}}$ \\ ${ }^{1}$ Department of Clinical Biochemistry, Faculty of Medical Sciences, Tarbiat Modares University, Tehran, Iran \\ ${ }^{2}$ Department of Biology, Faculty of Science, University of Sistan and Baluchestan, Zahedan, Iran \\ "Corresponding author: Department of Clinical Biochemistry, Faculty of Medical Sciences, Tarbiat Modares University, P.O. Box: 14115-331, Tehran, Iran. Email: \\ nassim_faridi@yahoo.com \\ "Corresponding author: Department of Biology, Faculty of Science, University of Sistan and Baluchestan, Zahedan, Iran. Email: arezou@chem.usb.ac.i \\ Received 2018 July 08; Revised 2018 October 23; Accepted 2018 October 24.
}

\begin{abstract}
Heat shock protein 90 (HSP90) serves an essential role in stability and function of over-expressed proteins that promote malignancy. HSP90 guides various cellular and physiological processes/functions such as cell growth, cell survival and differentiation, hormone signaling, trafficking, response to cellular stress, and apoptosis. Conversely, HSP9o during oncogenesis causes malignant transformation and is critical for the maintenance and maturation of a broad range of mutated proteins activated and/or over-expressed in signaling pathways, promoting cancer cell growth and/or survival. Therefore, HSP9O is an attractive target strategy for tumor treatment. We described HSP90 structure and function in normal cells and in malignancy.
\end{abstract}

Keywords: Chaperones, Heat Shock Protein 90, Cancer

\section{Context}

In the early 1960s, heat-shock proteins (HSPs) were discovered by Ritossa. Cellular and molecular biology of HSPs has generated a very active area of research (1), and the first general concept of molecular HSPs was presented by Ellis and van der Vies in 1987 (2). The highly conserved family of stress proteins, called heat-shock proteins (HSPs), are induced by cellular and environmental stress, including high temperature, hypoxic damage, and oxidative stress (3). Despite their name "heat shock or stress proteins", they are expressed ubiquitously under normal conditions. HSP90 content of cells in non-stressful conditions is 1\% - $2 \%$ of whole cellular protein, and in response to stressful conditions, it rises by about twofold (4\% - 6\%) (1).

HSPs have important cellular activity in both stress protection and housekeeping tasks, such as protein biosynthesis and de novo folding, proteins translocation across membranes, normal protein turnover, quality control of proteins in the endoplasmic reticulum (ER), proteins translocation across membranes, post-translational regulation of signaling molecules, the assembly/disassembly of transcriptional complexes, and the processing of immunogenic peptides by the immune system $(1,4-6)$.

HSPs, also called chaperones that help proteins to achieve their correct folding, are different in their cellular localization, function, and molecular weight $(7,8)$. According to molecular size, HSPs, are classified into various fam- ilies such as HSP100, HSP90, HSP70, HSP60, and small HSPs (15 - $30 \mathrm{kDa}$ )(9). Adenosine triphosphate (ATP)-dependents are high molecular-weight HSPs (10).

Although functional conformation of a protein is determined by its amino acid residues, most polypeptides are unable to fold properly when highly concentrated without the assistance of molecular chaperones. Normal levels of HSPs facilitate folding of proteins to the native folded state and protect them from misfolding and aggregation (1). An overview of chaperones mediating post-translational protein homeostasis is presented schematically in Figure 1.

The majority of HSP90s, known as cellular substrates, are signal transducers of proteins and play a crucial role in growth control and cell survival (12). These HSPs include serine/threonine kinas (Cdk-4 and Raf-1), steroid hormone receptors, receptor tyrosine kinas (13-16), AKT (17), HIF1 $\alpha$ (18), MMp2 (19), transcription factors such as MyoD, tyrosine kinases such as Her-2/neu, and mutant transcription factors such as p53 in cancerous and noncancerous cells $(20,21)$.

Several detailed studies are available that address the structural and molecular biology and function of HSPs in general (22-26) and HSP9o in particular (27).

It is known that in many solid tumors and hematological malignancies, HSPs are increased. In malignant cells, HSPs are expressed to protect and retain protein homoeostasis from the hostile hypoxic and acidotic microen-

Copyright (c) 2018, Gene, Cell and Tissue. This is an open-access article distributed under the terms of the Creative Commons Attribution-NonCommercial 4.0 International License (http://creativecommons.org/licenses/by-nc/4.0/) which permits copy and redistribute the material just in noncommercial usages, provided the original work is properly cited. 


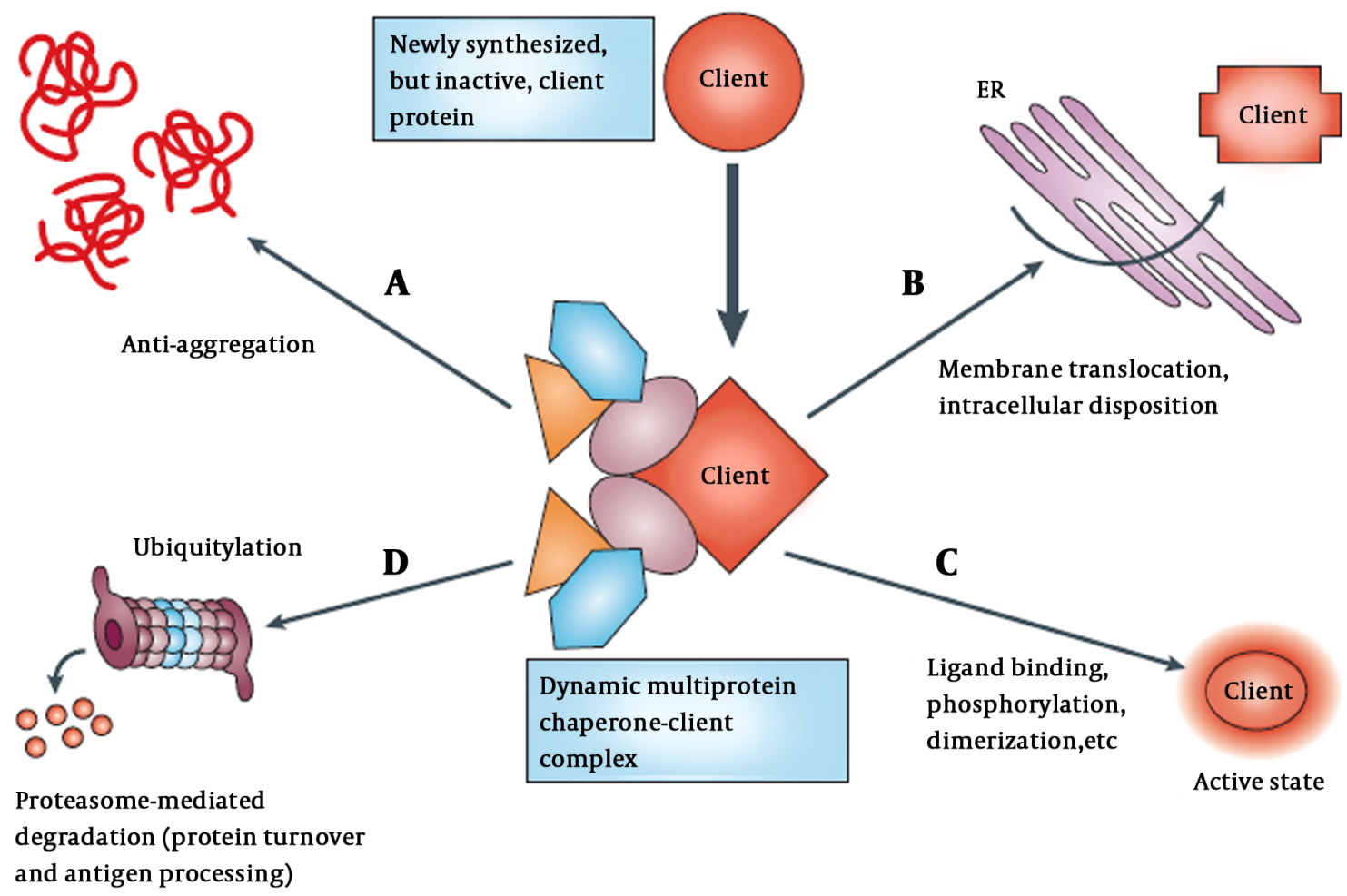

Figure 1. Chaperones participate in regulating various cellular process (11). A, Newly synthesized proteins associated with chaperones and co-chaperones (different color shapes); B, that also help with translocation and trafficking of protein across membranes such as endoplasmic reticulum (ER); C, chaperones maintain proteins in meta-state (active or stable state) by stimuli in multi-subunit signaling complexes; D, chaperone target protein to degradation through the ubiquitin-proteasome pathway in the absence of appropriate stimuli.

vironment of the tumor. Furthermore, tumor cells can use HSPs to tolerate fatal genetic mutations (28). Therefore, inhibitors that target HSPs may disrupt multiple oncogenic processes and influence HSPs to change their function and cause degradation of their oncogenic 'client' proteins by proteasome (29).

The main objective of this review was to describe the structure and function of HSP9O and then discuss the importance of HSP90 for the regulation of various processes associated with malignancy. We also reviewed how HSP90 inhibitors can target its structure and may be as useful as drugs.

\section{HSP90 Structure and Function}

HSP90, one of the most common cellular chaperones, is a multi-component machine of chaperone proteins that requires some proteins like p60/Hop, p50Cdc37, HSP40/HDJ2, p23, and HSP70 and a variety of immunophilins to function (30, 31). HSP90 mainly exists as a homodimer consisting of monomers comprising of three main functional domains that display important functional interactions (32). HSP90 is a cell surface HSP secreted from cells that perform specific immunological functions (33-36). HSP9o has five organelle-specific isoforms, including cytoplasmic $\operatorname{HSP} 90 \alpha$ - and $\beta$-isoforms, endoplasmic reticulum localized glucose-regulated protein 94 (GRP94), mitochondrial tumor necrosis factor receptor-associated protein 1 (TRAP1), and membraneassociated HSP9ON (9). Two distinct genes encode HSP90 $\alpha$ and HSP90 $\beta$ (37).

In humans, two HSP90 isoforms exist in the cytosol, an inducible (HSP90 $\alpha$ ) and a constitutive form (HSP90 $\beta$ ), which are stress-inducible and closely related with no differences in their activities $(38,39)$. The cytosolic isoform of HSP90 is involved in cancer. HSP9o level is regulated by heat shock transcription factor-1 (HSF) that interacts with it (40). Four isoforms of HSP90, except HSP90N, are highly similar in structure (9). Several posttranslational modifications such as phosphorylation, nitrosylation, and acety- 
lation regulate HSP9o function (41).

HSP90, like other molecular chaperones, rarely functions alone and is a component of a larger machine. It has a highly flexible and dynamic molecule that works with other chaperones, co-chaperones, ATPase activity modulators, and different accessory proteins. As an energy source, it hydrolyzes ATP (42). In normal physiological conditions, HSP90 forms a $90 \mathrm{kDa}$ MW homodimer. Each protomer consists of three structural and functional domains. As shown in Figure 2, the N-terminal domain (NTD) or ATP-binding domain, middle-domain (MD) or ATP-hydrolysis regulating domain, and C-terminal domain (CTD) or dimerization domain of HSP9o have been reported (43). Some members of HSP90 family such as cytosolic HSP9o have a disordered region, termed as the charged linker, which separates NTD and MD domains. The NTD possesses an adenine nucleotide-binding pocket. ATP binds in N-terminal pocket of the chaperone (32).

Eukaryotic cytosolic HSP9os have a C-terminal extension of MEEVD. This structural motif belongs to the GHKL superfamily. Hydrolysis of ATP to ADP plays an essential role in HSP90 dimer chaperoning activity (45). The CDC37A fragment of the co-chaperone p50 makes a complex with the N-terminus of HSP90. This co-chaperone recruits kinases to the HSP9O machinery (46).

In eukaryotes, a flexible and highly charged linker sequence connects N-terminal domain to the 'middle region' of HSP90. The middle region serves an important function in the binding of client proteins to HSP90, it also interacts with the $\gamma$-phosphate group of ATP molecules and modulates ATP hydrolysis $(45,47)$. Protein AHA1 (activator of HSP90 ATPase homologue 1) acts as a co-chaperone and causes an association between the $\mathrm{N}$-terminal and middle domains. When it binds to HSP90, the ATP-hydrolysis rate of HSP90 markedly accelerates (48). A second flexible linker of HSP9o forms its inherent dimeric status and is responsible for connection between the middle region and the $12 \mathrm{kDa}$ C-terminal domain of HSP90.

The COOH-terminal end of this region provides a second ATP-binding site on HSP9o and regulates ATPase activity (47). Finally, C-terminal recruits diverse tetratricopeptide-containing repeats (TPR)-domain and contains co-chaperones such as immunophilins, HSP70/HSP90-organizing protein (HOP), protein phosphatase 5 (PP5), PPIase, and non-TPR co-chaperones CD37, p23, and AHA1 through a conserved EEVD motif. These proteins modify and increase the specificity of HSP90containing complexes, modulate ATPase activity, and are involved in client protein maturation. ATP hydrolysis occurs slowly by HSP90 (49).

The p50 (yeast homolog Cdc37) and p23 (yeast homolog Sba1), as co-chaperones, are also connected to NTD
(50), which has partial ATPase activity. MD has a catalytic residue, Arg380, that orientates and polarizes ATP $\gamma$ phosphate (45) and provides a binding site for client proteins such as eNOS, Akt, linker polypeptides of phycobilisome, Cdk4, and staphylococcal nuclease $(51,52)$ and cochaperones such as Aha1 (48). The CTD plays a critical role in HSP90 dimerization and binding client proteins such as the tumor suppressor p53 (53).

HSP90 adopts various conformational states. These states include apo (when HSP9o is nucleotide-free), open (when it connects to ATP), AMPPNP or closed (when connected to ADP), and Grp94-like (54). Binding and hydrolysis of ATP drive the conformational changes and manage the time period of ATPase cycle. In vivo function of HSP90 is ATP-dependent, indicating that ATPase cycle serves a critical role in cellular function of $\operatorname{HSP} 90(55,56)$. ATP binds to HSP90 in an apo state, and then the N-terminal domain of each protomer binds together and forms a dimer or closed catalytically active state (the ATP state). When ATP is hydrolyzed (the ADP state), HSP90 releases ADP and returns to open state (Figure 1). Hydrolysis of ATP to ADP induces structural alterations and chaperoning activity of HSP9O $(55,56)$.

HSP90 functions and interactions with its clients can allow cells to link to its environment, and stress response is coupled with the integrated changes in signaltransduction pathways and transcriptional responses (5). Epigenetic changes in gene expression and heritable alterations in chromatin state can be induced by HSP9O (57). One of the several chromatin-remodeling complexes is DNA helicase, which interacts with HSP9O co-factors and support the link between HSP90 and epigenetic regulation of gene function (58). HSP90 activity can hide inherent polymorphisms within populations of organisms (59). As a result, polymorphic variants of HSP90 client proteins involved in crucial signaling pathways accumulate, while it functions to maintain wild-type phenotypes (60). The lessstable HSP9o client proteins might become more unstable under different stressful conditions. Afterward, HSP90 increases refolding demand of its usual client proteins, as well as new and stress-destabilized ones. Genetic variation cache increases buffering capacity of HSP90, and despite underlying genotypic variations, it produces diverse and genotype-specific phenotypes (61). In this way, populations with hidden genetic variations and distinct genotypes survive owing to natural selection (62). Similarly, at the protein level, HSP90 might act as cancer chaperone buffering of mutant protein and produce one of the characteristics of cancers known as genetic heterogeneity $(28,61)$.

Recently, X-ray diffraction studies showed when calcium and magnesium compete for free ATP concentration, calcium supports TRAP1 ATPase activity and compensates 


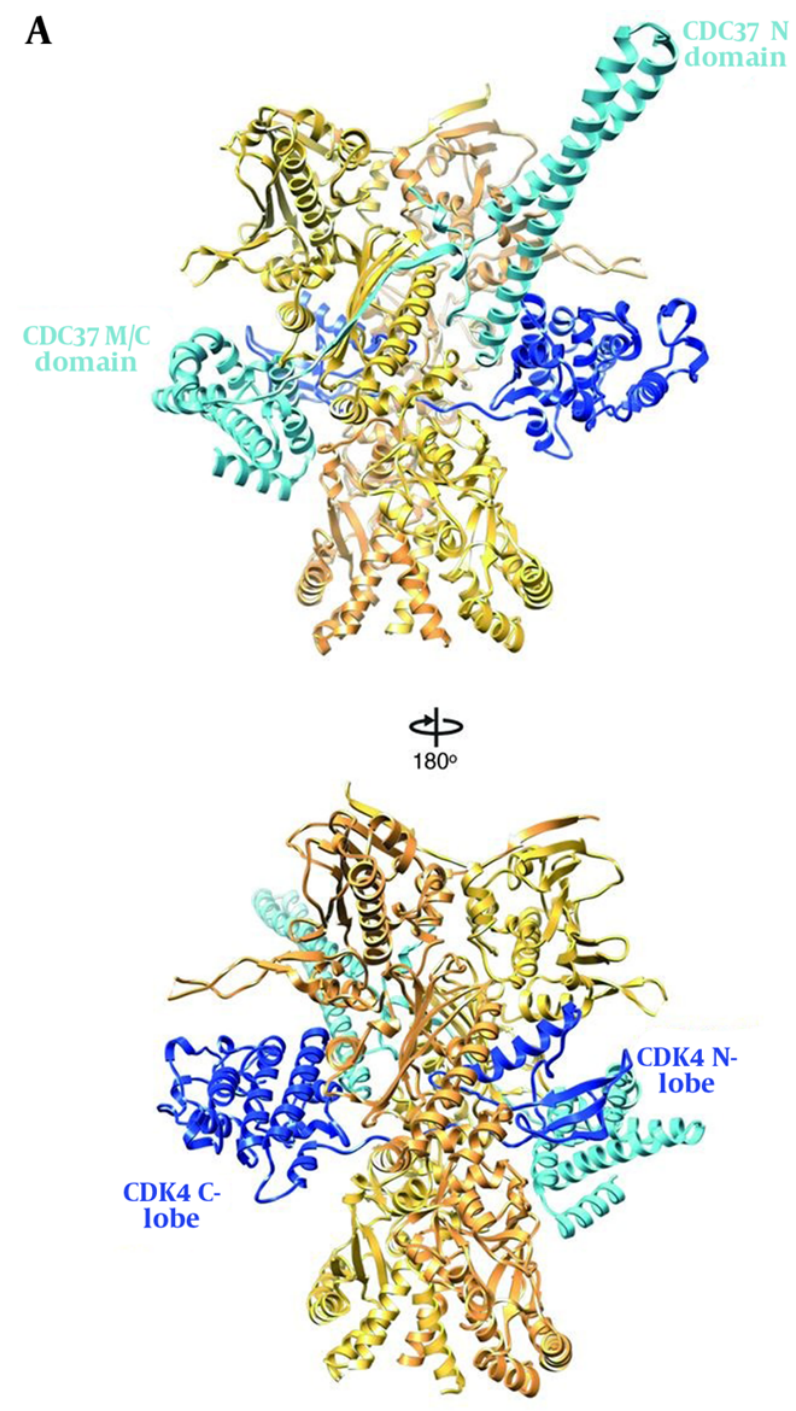

B
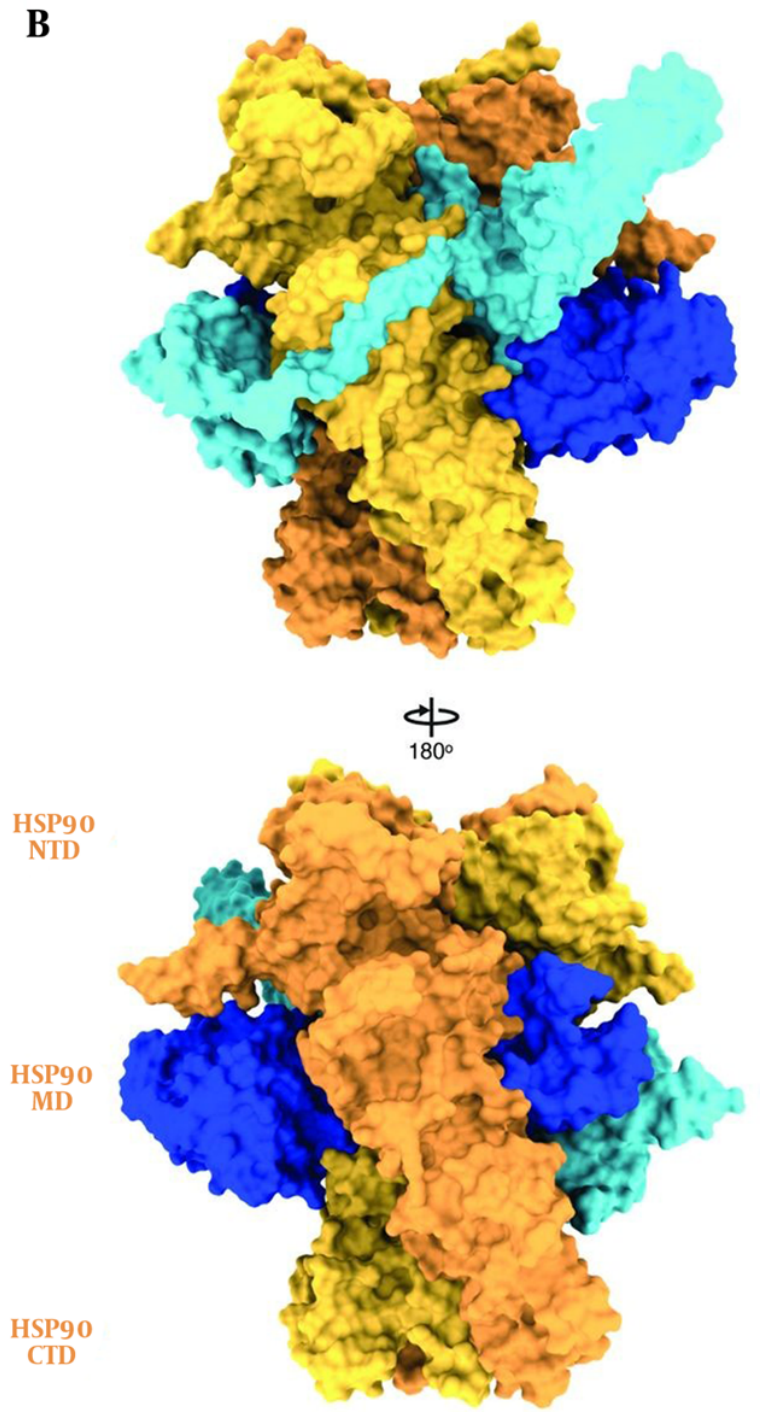

Figure 2. Hsp90 and its domains in the complex. A, Ribbon representation and B, surface representation (44).

for magnesium (63). In malignant tissues, there are contrasting reports regarding the expression of TRAP1 patterns (64). The mutation of TRAP1 increases mitochondrial ATP production and respiration (65). In addition, GRP94 expression was clinically indicative of advanced stage in many cancers like gallbladder cancer (66) and colon cancer (67).

Additionally, HSP90 $\beta$ genetic mutation decreased differentiation of induced pluripotent stem cells to hepatocyte (68). Consequently, phenotypic diversity and evolution of invasive, metastatic, and drug-resistant biologies would increase within the cancer cell population. As a result, HSP90 might provide a useful target for anticancer therapies (69).

\section{The Heat-Shock Response (HSR)}

The rapid induction of HSPs in response to various stressful conditions is a set of well-ordered and regulated responses known as HSR, which occur in coordinated series of genetic and biochemical events. Transcription regulators, which are called heat shock factors (HSFs), mediate HSR and regulate the expression of heat shock proteins and responsive genes. In humans, three HSFs, HSF1, 2 and 4, have been isolated. HSF1, most crucial to HSR, binds to HSP90, while in response to stress, it rapidly 
dissociates from its complex with HSP90 and HSP70 and becomes activated $(9,70)$. Transcription of HSP mRNA proceeds in stressful environments with ATP-independent post-translational modification since its mRNA lacks introns. Increased levels of HSPs are present in many types of cancer $(11,28)$.

Heat-shock proteins drive tumor growth, metastasis, and cell survival. In growth factor-deprived conditions, it allows cancer cells to translate protein and proliferate (11). Similarly, depletion of HSF1 reduces viability of cancer cells, while showing no effect on normal cells that suggests HSF1 provides critical relief for cancer cells in stressful conditions (71). HSF1 promotes tumorigenesis by mediating HSP induction and organizing a wide network of cellular functions such as energy metabolism, cell growth, survival, and protein synthesis $(71,72)$.

In cellular stress conditions, HSF, after separation from HSP90, is phosphorylated by protein kinases, and trimers molecules are formed that are able to enter the nucleus and bind to the promoter region of the HSP9O and other HSP genes. Additional phosphorylation of HSF proceeds transcription of HSP9O mRNA and causes its translocation to cytosol, where a new HSP90 chaperone complex is assembled (40).

\section{HSPs Alterations in Malignancy}

In many tumors, elevated expression of chaperone proteins is observed, and cancer cells maintain homeostasis and tolerate alterations within their stressful microenvironments. Mutations in critical signaling molecules help to drive oncogenesis chaperones serve as biochemical buffers for genetic lesions found within most human cancers (73). The increased expression of HSPs is a common feature in a range of cancers (solid and hematological malignancies) and confers a proper cytoprotective stress response to some malignant tumor characteristics such as hostile hypoxic, acidosis, and nutrient-deprived microenvironment $(73,74)$. In breast cancer, HSP70 and HSP90 overexpression is correlated with poor prognosis (75), resistance, and low response to drug and regimens of combination chemotherapy (76).

At the molecular level, increased chaperone activities allow cells to escape apoptotic death and assist in coping with the imbalanced signaling in neoplastic transformation $(73,74)$. Apoptotic signaling is significantly impaired in cancer cells. Chaperones enable cancer cells to have independent normal regulatory factors and escape from host defense mechanisms and chemotherapeutic drugs, which result in bypass death mechanism and survival and expansion of cancer cell $(77,78)$. HSP90 and its cochaperones are tumor cell apoptosis modulators. Most of their effects seem to be mediated through AKT (17), tumornecrosis factor (TNF) receptors (79), and nuclear factor- $\kappa \mathrm{B}$ $(\mathrm{NF}-\kappa \mathrm{B})$ function (80). However, neoplastic transformation and apoptosis inhibition are facilitated by HSP90. The dynamic and low binding affinity of HSP9O with its clients play a key role in maintenance of the latent, but readily activated, state (42).

The unstable conformational state of the clients' oncogenic mutant leads to increased HSP9o function requirements. The most dramatic example of this phenomenon is SRC tyrosine kinase. The C-terminus truncation of the oncogenic SRC mutant results in the deletion of its essential regulatory domain and a constitutively active, but conformationally unstable, kinase. This domain is normally responsible for interaction with $\mathrm{SH} 2$ domain, kinase activity repression, and structural stabilization in the protein (81). Limited HSP90 machinery assistance is required for normal c-SRC maturation and function, whereas v-SRC mutants are aberrantly and physically associate with HSP90, which is essential to acquire and maintain increased and transforming kinase activity of v-SRC (82).

The most common molecular genetic defect is p53 mutations found in many human cancers. Most mutations in TP53 result in conformational changes of its protein and altered cell-cycle-checkpoint activity. The wild-type p53 undergoes transient interactions with HSP90 to maintain its activation-competent conformation and regulate its degradation by the ubiquitin-proteasome system (83, 84). Most p53 mutants adopt aberrant conformations, interact extendedly with the chaperone, and prevent their normal degradation and dysfunctional proteins accumulation (a pathological hallmark of mutation) within tumor cells (85). Mutant p53 proteins do not act as tumor suppressors and form heterodimers (dominant-negative effect) with normal p53 and interfere with its function or transactivate other genes that have tumor-promoting effects. Cancer cells overexpress matrix metalloproteinase2 (MMP-2) and secret HSP90 $\alpha$ into the extracellular matrix and assist in the activation of MMP-2 and invasion (86).

Natural products such as geldanamycin (GA), radicicol, and a growing number of semisynthetic and synthetic derivatives bound in ATP pocket with higher affinity than nucleotides can lock the domain in its ADP-bound conformation. Therefore, many of normal functions of the chaperone alter (87). In particular, inhibition of ADP conformation of Hsp90 recruit E3 ubiquitin ligases such as CHIP (carboxy-terminus of HSP70-interacting protein) that HSP90 normally chaperone (88). Many client proteins are degraded by proteasomes and protein depletion occurs in cells $(45,47)$.

Ablation of the function of chaperones has lethal effects on both normal and cancer cells. Therefore, drugs 
with extremely high affinity and specificity may not lead to improvements of the therapeutic index. Because chaperones participate in many critical functions, their mutation is the leading cause of drug resistance. Some chaperone inhibitors disrupt multiple oncogenic chaperone client proteins, which can be a unique and therapeutically attractive feature (28).

ATP-binding pocket with small molecules (novobiocin, GA, an ansamycin lead compound) destabilize HSP90 client proteins, and flexible linkers and co-chaperones such as p50 provide a target for the discovery and production of novel HSP9o inhibitors $(4,28,46,49)$.

Despite the anti-cancer activity of GA in many in vivo and in vitro studies, because of its structural instability and hepatotoxicity, its clinical usage has not yet been approved. In in vitro studies, GA is still commonly used to inhibit HSP90 (89).

Chaperone proteins play a role in initiating and maintaining transformed phenotypes or risk of transformation (90). During the past decade, the molecular chaperone, HSP90, has become a target for several small-molecule drugs identified as potential anticancer agents. These drugs disrupt numerous receptor functions, transcription factors, and kinases known to be involved in the development of oncogenesis (11).

\section{Conclusions}

In this study, the main focus was to study the structure and function of HSP9O as an important member of HSPs. HSP90 proteins are highly dynamic machines, in which multiple posttranslational modifications and binding to different co-chaperones regulate their structure and function. HSP9O appears to be overexpressed in cancer cells. A diverse set of client proteins of HSP90 are crucial in many cellular functions and participate in survival signals, proangiogenic signals, cell cycle checkpoints, proliferation, and metastasis that are heavily involved in creating and maintaining the malignant phenotype. Therefore, HSP90 inhibition might be particularly useful as a treatment of human cancer cells.

\section{Footnotes}

Authors' Contribution: Study concept and design: Nassim Faridi, Arezou Ghahghaei; drafting of the manuscript: Nassim Faridi; critical revision of the manuscript for important intellectual content: Arezou Ghahghaei, Nassim Faridi.

Funding/Support: This research received no specific grant from any funding agency in the public and commercial.

\section{References}

1. Wegele H, Muller L, Buchner J. Hsp70 and Hsp90-a relay team for protein folding. Rev Physiol Biochem Pharmacol. 2004;151:1-44. doi: 10.1007/s10254-003-0021-1. [PubMed: 14740253].

2. Ellis RJ, van der Vies SM. Molecular chaperones. Annu Rev Biochem. 1991;60:321-47. doi: 10.1146/annurev.bi.60.070191.001541. [PubMed 1679318].

3. Young JC, Agashe VR, Siegers K, Hartl FU. Pathways of chaperonemediated protein folding in the cytosol. Nat Rev Mol Cell Biol. 2004;5(10):781-91. doi: 10.1038/nrm1492. [PubMed:15459659].

4. Marcu MG, Schulte TW, Neckers L. Novobiocin and related coumarins and depletion of heat shock protein 90-dependent signaling proteins. J Natl Cancer Inst. 2000;92(3):242-8. [PubMed: 10655441].

5. Freeman BC, Yamamoto KR. Disassembly of transcriptional regulatory complexes by molecular chaperones. Science. 2002;296(5576):2232-5. doi: 10.1126/science.1073051. [PubMed: 12077419].

6. Picard D, Khursheed B, Garabedian MJ, Fortin MG, Lindquist S, Yamamoto KR. Reduced levels of hsp90 compromise steroid receptor action in vivo. Nature. 1990;348(6297):166-8. doi: 10.1038/348166a0. [PubMed: 2234079].

7. Hartl FU, Hayer-Hartl M. Molecular chaperones in the cytosol: From nascent chain to folded protein. Science. 2002;295(5561):1852-8. doi: 10.1126/science.1068408. [PubMed: 11884745].

8. Morimoto RI, Kline MP, Bimston DN, Cotto JJ. The heat-shock response: Regulation and function of heat-shock proteins and molecular chaperones. Essays Biochem. 1997;32:17-29. [PubMed: 9493008].

9. Powers MV, Workman P. Inhibitors of the heat shock response: Biology and pharmacology. FEBS Lett. 2007;581(19):3758-69. doi: 10.1016/j.febslet.2007.05.040. [PubMed:17559840].

10. Jakob U, Gaestel M, Engel K, Buchner J. Small heat shock proteins are molecular chaperones. J Biol Chem. 1993;268(3):1517-20. [PubMed: 8093612].

11. Whitesell L, Lindquist SL. HSP90 and the chaperoning of cancer. Nat Rev Cancer. 2005;5(10):761-72. doi: 10.1038/nrc1716. [PubMed:16175177].

12. Pratt WB. The hsp9o-based chaperone system: Involvement in signal transduction from a variety of hormone and growth factor receptors. Proc Soc Exp Biol Med. 1998;217(4):420-34. [PubMed: 9521088].

13. Messaoudi S, Peyrat JF, Brion JD, Alami M. Recent advances in Hsp90 inhibitors as antitumor agents. Anticancer Agents Med Chem. 2008;8(7):761-82. [PubMed: 18855578].

14. Munster PN, Marchion DC, Basso AD, Rosen N. Degradation of HER2 by ansamycins induces growth arrest and apoptosis in cells with HER2 overexpression via a HER3, phosphatidylinositol 3'-kinaseAKT-dependent pathway. Cancer Res. 2002;62(11):3132-7. [PubMed: 12036925].

15. Schulte TW, Blagosklonny MV, Romanova L, Mushinski JF, Monia BP, Johnston JF, et al. Destabilization of Raf-1 by geldanamycin leads to disruption of the Raf-1-MEK-mitogen-activated protein kinase signalling pathway. Mol Cell Biol. 1996;16(10):5839-45. [PubMed: 8816498]. [PubMed Central: PMC231585].

16. Stepanova L, Leng X, Parker SB, Harper JW. Mammalian p50Cdc37 is a protein kinase-targeting subunit of Hsp90 that binds and stabilizes Cdk4. Genes Dev.1996;10(12):1491-502. [PubMed: 8666233].

17. Redlak MJ, Miller TA. Targeting PI3K/Akt/HSP9o signaling sensitizes gastric cancer cells to deoxycholate-induced apoptosis. Dig Dis Sci. 2011;56(2):323-9. doi: 10.1007/s10620-010-1294-2. [PubMed: 20585984].

18. Onnis B, Rapisarda A, Melillo G. Development of HIF-1 inhibitors for cancer therapy. J Cell Mol Med. 2009;13(9A):2780-6. doi: 10.1111/j.1582-4934.2009.00876.x. [PubMed: 19674190]. [PubMed Central: PMC2832082] 
19. Stellas D, El Hamidieh A, Patsavoudi E. Monoclonal antibody $4 \mathrm{C} 5$ prevents activation of MMP2 and MMP9 by disrupting their interaction with extracellular HSP90 and inhibits formation of metastatic breast cancer cell deposits. BMC Cell Biol. 2010;11:51. doi:10.1186/1471-2121-11-51. [PubMed: 20602761]. [PubMed Central: PMC2914660].

20. Richter K, Buchner J. Hsp90: Chaperoning signal transduction. J Cell Physiol. 2001;188(3):281-90. doi: 10.1002/jcp.1131. [PubMed: 11473354].

21. Stebbins CE, Russo AA, Schneider C, Rosen N, Hartl FU, Pavletich NP. Crystal structure of an Hsp90-geldanamycin complex: Targeting of a protein chaperone by an antitumor agent. Cell. 1997;89(2):239-50. [PubMed: 9108479].

22. Ghahghaei A, Bathaie SZ, Bahraminejad E. Mechanisms of the effects of crocin on aggregation and deposition of $A \beta 1-40$ fibrils in Alzheimer's disease. Int J Pept Res Ther. 2012;18(4):347-51. doi: 10.1007/s10989-012-9308-x.

23. Ghahghaei A, Bathaie SZ, Kheirkhah H, Bahraminejad E. The protective effect of crocin on the amyloid fibril formation of Abeta42 peptide in vitro. Cell Mol Biol Lett. 2013;18(3):328-39. doi: 10.2478/s11658-0130092-1. [PubMed: 23737042].

24. Ghahghaei A, Bathaie SZ, Shahraki A, Rahmany Asgarabad F. Comparison of the chaperoning action of glycerol and $\beta$-casein on aggregation of proteins in the presence of crowding agent. Int J Pept Res Ther. 2011;17(2):101-11. doi: 10.1007/s10989-011-9247-y.

25. Ghahghaei A, Divsalar A, Faridi N. The effects of molecular crowding on the amyloid fibril formation of alpha-lactalbumin and the chaperone action of alpha-casein. Protein J. 2010;29(4):257-64. doi: 10.1007/s10930-010-9247-3. [PubMed: 20496103].

26. Ghahghaei A, Mohammadian S. The effect of Arg on the structure perturbation and chaperone activity of alpha-crystallin in the presence of the crowding agent, dextran. Appl Biochem Biotechnol. 2014;174(2):739-50. doi: 10.1007/s12010-014-1092-y. [PubMed: 25091326].

27. Pratt WB, Toft DO. Regulation of signaling protein function and trafficking by the hsp90/hsp70-based chaperone machinery. Exp Biol Med (Maywood). 2003;228(2):111-33. [PubMed: 12563018].

28. Bagatell R, Whitesell L. Altered Hsp9o function in cancer: A unique therapeutic opportunity. Mol Cancer Ther. 2004;3(8):1021-30. [PubMed: 15299085].

29. Solit DB, Chiosis G. Development and application of Hsp90 inhibitors. Drug Discov Today. 2008;13(1-2):38-43. doi: 10.1016/j.drudis.2007.10.007. [PubMed:18190862].

30. Pratt WB, Toft DO. Steroid receptor interactions with heat shock protein and immunophilin chaperones. Endocr Rev. 1997;18(3):306-60. doi: 10.1210/edrv.18.3.0303. [PubMed: 9183567].

31. Young JC, Moarefi I, Hartl FU. Hsp90: A specialized but essential protein-folding tool.JCell Biol.2001;154(2):267-73. [PubMed:11470816]. [PubMed Central: PMC2150759].

32. Dutta R, Inouye M. GHKL, an emergent ATPase/kinase superfamily. Trends Biochem Sci. 2000;25(1):24-8. doi: 10.1016/s09680004(99)01503-0.

33. Calderwood SK, Gong J, Murshid A. Extracellular HSPs: The complicated roles of extracellular HSPs in immunity. Front Immunol. 2016;7:159. doi: 10.3389/fimmu.2016.00159. [PubMed: 27199984]. [PubMed Central: PMC4842758].

34. Tsutsumi S, Neckers L. Extracellular heat shock protein 90: A role for a molecular chaperone in cell motility and cancer metastasis. Cancer Sci. 2007;98(10):1536-9. doi: 10.1111/j.1349-7006.2007.00561.x. [PubMed: 17645779].

35. Ullrich SJ, Robinson EA, Law LW, Willingham M, Appella E. A mouse tumor-specific transplantation antigen is a heat shockrelated protein. P Natl Acad Sci (PNAS). 1986;83(10):3121-5. doi: 10.1073/pnas.83.10.3121.

36. Lee J, Zhang LL, Wu W, Guo H, Li Y, Sukhanova M, et al. Activation of MYC, a bona fide client of HSP90, contributes to intrinsic ibrutinib resistance in mantle cell lymphoma. Blood Adv. 2018;2(16):2039-51. doi:10.1182/bloodadvances.2018016048.[PubMed:30115641]. [PubMed
Central: PMC6113611].

37. Sreedhar AS, Kalmar E, Csermely P, Shen YF. Hsp90 isoforms: Functions, expression and clinical importance. FEBS Lett. 2004;562(1-3):115. [PubMed: 15069952].

38. Csermely P, Schnaider T, So"ti C, Prohászka Z, Nardai G. The 90-kDa molecular chaperone family: Structure, function, and clinical applications. A comprehensive review. Pharmacol Ther. 1998;79(2):129-68. doi: 10.1016/s0163-7258(98)00013-8.

39. Hickey E, Brandon SE, Sadis S, Smale G, Weber LA. Molecular cloning of sequences encoding the human heat-shock proteins and their expression during hyperthermia. Gene. 1986;43(1-2):147-54. [PubMed: 3019832].

40. Goetz MP, Toft DO, Ames MM, Erlichman C. The Hsp9o chaperone complex as a novel target for cancer therapy. Ann Oncol. 2003;14(8):1169-76. [PubMed: 12881371].

41. Wandinger SK, Richter K, Buchner J. The Hsp9o chaperone machinery. J Biol Chem. 2008;283(27):18473-7. doi: 10.1074/jbc.R800007200. [PubMed: 18442971].

42. Smith DF, Whitesell L, Nair SC, Chen S, Prapapanich V, Rimerman RA. Progesterone receptor structure and function altered by geldanamycin, an hsp90-binding agent. Mol Cell Biol.1995;15(12):6804-12. [PubMed: 8524246]. [PubMed Central: PMC230934].

43. Prodromou C, Roe SM, O’Brien R, Ladbury JE, Piper PW, Pearl LH. Identification and structural characterization of the ATP/ADP-binding site in the Hsp90 molecular chaperone. Cell. 1997;90(1):65-75. [PubMed: 9230303].

44. Verba KA, Wang RY, Arakawa A, Liu Y, Shirouzu M, Yokoyama S, et al. Atomic structure of Hsp90-Cdc37-Cdk4 reveals that Hsp9o traps and stabilizes an unfolded kinase. Science. 2016;352(6293):1542-7. doi: 10.1126/science.aaf5023. [PubMed: 27339980]. [PubMed Central: PMC5373496].

45. Meyer P, Prodromou C, Hu B, Vaughan C, Roe SM, Panaretou B, et al. Structural and functional analysis of the middle segment of hsp90: Implications for ATP hydrolysis and client protein and cochaperone interactions. Mol Cell. 2003;11(3):647-58. [PubMed: 12667448].

46. Pearl LH. Hsp90 and Cdc37-a chaperone cancer conspiracy. Curr Opin Genet Dev. 2005;15(1):55-61. doi: 10.1016/j.gde.2004.12.011. [PubMed: 15661534].

47. Soti C, Racz A, Csermely P. A Nucleotide-dependent molecular switch controls ATP binding at the C-terminal domain of Hsp90. N-terminal nucleotide binding unmasks a C-terminal binding pocket. $J$ Biol Chem. 2002;277(9):7066-75. doi: 10.1074/jbc.M105568200. [PubMed: 11751878].

48. Meyer P, Prodromou C, Liao C, Hu B, Mark Roe S, Vaughan CK, et al. Structural basis for recruitment of the ATPase activator Aha1 to the Hsp90 chaperone machinery. EMBO J. 2004;23(3):511-9. doi: 10.1038/sj.emboj.7600060. [PubMed: 14739935]. [PubMed Central: PMC1271799].

49. Scheufler C, Brinker A, Bourenkov G, Pegoraro S, Moroder L, Bartunik H, et al. Structure of TPR domain-peptide complexes: Critical elements in the assembly of the Hsp70-Hsp90 multichaperone machine. Cell. 2000;101(2):199-210. doi: 10.1016/S0092-8674(00)80830-2. [PubMed: 10786835].

50. Roe SM, Ali MM, Meyer P, Vaughan CK, Panaretou B, Piper PW, et al. The mechanism of Hsp90 regulation by the protein kinase-specific cochaperone p50(cdc37). Cell. 2004;116(1):87-98. [PubMed: 14718169].

51. Street TO, Lavery LA, Agard DA. Substrate binding drives largescale conformational changes in the Hsp90 molecular chaperone. Mol Cell. 2011;42(1):96-105. doi: 10.1016/j.molcel.2011.01.029. [PubMed: 21474071]. [PubMed Central: PMC3105473].

52. Vaughan CK, Gohlke U, Sobott F, Good VM, Ali MM, Prodromou C, et al. Structure of an Hsp90-Cdc37-Cdk4 complex. Mol Cell. 2006;23(5):697707. doi: 10.1016/j.molcel.2006.07.016. [PubMed: 16949366]. [PubMed Central: PMC5704897].

53. Hagn F, Lagleder S, Retzlaff M, Rohrberg J, Demmer O, Richter K, et 
al. Structural analysis of the interaction between Hsp9o and the tumor suppressor protein p53. Nat Struct Mol Biol. 2011;18(10):1086-93. doi: 10.1038/nsmb.2114. [PubMed: 21892170].

54. Shiau AK, Harris SF, Southworth DR, Agard DA. Structural analysis of E. coli Hsp9o reveals dramatic nucleotide-dependent conformational rearrangements. Cell. 2006;127(2):329-40. doi: 10.1016/j.cell.2006.09.027. [PubMed: 17055434].

55. Krukenberg KA, Street TO, Lavery LA, Agard DA. Conformational dynamics of the molecular chaperone Hsp90. Q Rev Biophys. 2011;44(2):229-55. doi: 10.1017/S0033583510000314. [PubMed: 21414251]. [PubMed Central: PMC5070531].

56. Prodromou C. The 'active life' of Hsp9o complexes. Biochim Biophys Acta. 2012;1823(3):614-23. doi: 10.1016/j.bbamcr.2011.07.020. [PubMed: 21840346]. [PubMed Central: PMC3793855].

57. Sollars V, Lu X, Xiao L, Wang X, Garfinkel MD, Ruden DM. Evidence for an epigenetic mechanism by which Hsp90 acts as a capacitor for morphological evolution. Nat Genet. 2003;33(1):70-4. doi: 10.1038/ng1067. [PubMed: 12483213].

58. Smith DF, Whitesell L, Katsanis E. Molecular chaperones: Biology and prospects for pharmacological intervention. Pharmacol Rev. 1998;50(4):493-514. [PubMed: 9860803].

59. Rutherford SL, Lindquist S. Hsp90 as a capacitor for morphological evolution. Nature. 1998;396(6709):336-42. doi: 10.1038/24550. [PubMed: 9845070].

60. Ruden DM, Garfinkel MD, Sollars VE, Lu X. Waddington's widget: Hsp90 and the inheritance of acquired characters. Semin Cell Dev Biol. 2003;14(5):301-10. [PubMed: 14986860].

61. Sangster TA, Lindquist S, Queitsch C. Under cover: Causes, effects and implications of Hsp90-mediated genetic capacitance. Bioessays. 2004;26(4):348-62. doi: 10.1002/bies.20020. [PubMed:15057933].

62. Rutherford SL. Between genotype and phenotype: Protein chaperones and evolvability. Nat Rev Genet. 2003;4(4):263-74. doi: 10.1038/nrg1041. [PubMed: 12671657].

63. Agard DA, Elnatan D. Modulation of mitochondrial Hsp90 (TRAP1)ATPase activity by calcium and magnesium. bioRxiv. 2018:300038. doi: $10.1101 / 300038$

64. Matassa DS, Agliarulo I, Avolio R, Landriscina M, Esposito F. TRAP1 regulation of cancer metabolism: Dual role as oncogene or tumor suppressor. Genes (Basel). 2018;9(4). doi: 10.3390/genes9040195. [PubMed: 29621137]. [PubMed Central: PMC5924537].

65. Fitzgerald JC, Zimprich A, Carvajal Berrio DA, Schindler KM, Maurer $B$, Schulte C, et al. Metformin reverses TRAP1 mutation-associated alterations in mitochondrial function in Parkinson's disease. Brain. 2017;140(9):2444-59. doi: 10.1093/brain/awx202. [PubMed: 29050400].

66. Chen Y, Chen C, Ma C, Sun S, Zhang J, Sun Y. Expression of heat-shock protein gp96 in gallbladder cancer and its prognostic clinical significance. Int J Clin Exp Pathol. 2015;8(2):1946-53. [PubMed: 25973087]. [PubMed Central: PMC4396202].

67. Pak MG, Koh HJ, Roh MS. Clinicopathologic significance of TRAP1 expression in colorectal cancer: A large scale study of human colorectal adenocarcinoma tissues. Diagn Pathol. 2017;12(1):6. doi: 10.1186/s13000-017-0598-3. [PubMed: 28088229]. [PubMed Central: PMC5237536].

68. Jing R, Duncan CB, Duncan SA. A small-molecule screen reveals that HSP9obeta promotes the conversion of induced pluripotent stem cell-derived endoderm to a hepatic fate and regulates HNF4A turnover. Development. 2017;144(10):1764-74. doi: 10.1242/dev.146845. [PubMed: 28360131]. [PubMed Central: PMC5450838].

69. Gatenby RA, Vincent TL. An evolutionary model of carcinogenesis. Cancer Res. 2003;63(19):6212-20. [PubMed: 14559806].

70. Xiao X, Zuo X, Davis AA, McMillan DR, Curry BB, Richardson JA et al. HSF1 is required for extra-embryonic development, postnatal growth and protection during inflammatory responses in mice. EMBO J. 1999;18(21):5943-52. doi: 10.1093/emboj/18.21.5943. [PubMed: 10545106]. [PubMed Central: PMC1171660].
71. Dai C, Whitesell L, Rogers AB, Lindquist S. Heat shock factor 1 is a powerful multifaceted modifier of carcinogenesis. Cell. 2007;130(6):100518. doi: 10.1016/j.cell.2007.07.020. [PubMed: 17889646]. [PubMed Central: PMC2586609].

72. Birch-Machin I, Gao S, Huen D, McGirr R, White RA, Russell S. Genomic analysis of heat-shock factor targets in Drosophila. Genome Biol. 2005;6(7):R63. doi: 10.1186/gb-2005-6-7-r63. [PubMed: 15998452]. [PubMed Central: PMC1175994].

73. Takayama S, Reed JC, Homma S. Heat-shock proteins as regulators of apoptosis. Oncogene. 2003;22(56):9041-7. doi: 10.1038/sj.onc.1207114. [PubMed: 14663482].

74. Mosser DD, Morimoto RI. Molecular chaperones and the stress of oncogenesis. Oncogene. 2004;23(16):2907-18. doi: 10.1038/sj.onc.1207529. [PubMed: 15077153].

75. Yano M, Naito Z, Tanaka S, Asano G. Expression and roles of heat shock proteins in human breast cancer. Jpn J Cancer Res. 1996;87(9):908-15. [PubMed: 8878452]. [PubMed Central: PMC5921196].

76. Trieb K, Gerth R, Holzer G, Grohs JG, Berger P, Kotz R. Antibodies to heat shock protein 90 in osteosarcoma patients correlate with response to neoadjuvant chemotherapy. Br J Cancer. 2000;82(1):857. doi: 10.1054/bjoc.1999.0881. [PubMed: 10638971]. [PubMed Central: PMC2363193].

77. Jaattela M. Escaping cell death: Survival proteins in cancer. Exp Cell Res. 1999;248(1):30-43. doi: 10.1006/excr.1999.4455. [PubMed. 10094811].

78. Sliutz G, Karlseder J, Tempfer C, Orel L, Holzer G, Simon MM. Drug resistance against gemcitabine and topotecan mediated by constitutive hsp70 overexpression in vitro: Implication of quercetin as sensitiser in chemotherapy. Br J Cancer. 1996;74(2):172-7. [PubMed: 8688318]. [PubMed Central: PMC2074570].

79. Vanden Berghe T, Kalai M, van Loo G, Declercq W, Vandenabeele P. Disruption of HSP90 function reverts tumor necrosis factorinduced necrosis to apoptosis. J Biol Chem. 2003;278(8):5622-9. doi 10.1074/jbc.M208925200. [PubMed: 12441346].

80. Chen G, Cao P, Goeddel DV. TNF-induced recruitment and activation of the IKK complex require Cdc37 and Hsp90. Mol Cell. 2002;9(2):40110. [PubMed: 11864612]

81. Falsone SF, Leptihn S, Osterauer A, Haslbeck M, Buchner J. Oncogenic mutations reduce the stability of SRC kinase. J Mol Biol 2004;344(1):281-91. doi: 10.1016/j.jmb.2004.08.091. [PubMed: 15504417].

82. Oppermann H, Levinson W, Bishop JM. A cellular protein that associates with the transforming protein of Rous sarcoma virus is also a heat-shock protein. Proc Natl Acad Sci U S A. 1981;78(2):1067-71. [PubMed: 6262754]. [PubMed Central: PMC319947].

83. Muller L, Schaupp A, Walerych D, Wegele H, Buchner J. Hsp90 regulates the activity of wild type p53 under physiological and elevated temperatures. J Biol Chem. 2004;279(47):48846-54. doi: 10.1074/jbc.M407687200. [PubMed:15358771].

84. Walerych D, Kudla G, Gutkowska M, Wawrzynow B, Muller L, King FW, et al. Hsp90 chaperones wild-type p53 tumor suppressor protein. J Biol Chem. 2004;279(47):48836-45. doi: 10.1074/jbc.M407601200. [PubMed: 15358769].

85. Whitesell L, Sutphin PD, Pulcini EJ, Martinez JD, Cook PH. The physical association of multiple molecular chaperone proteins with mutant p53 is altered by geldanamycin, an hsp90-binding agent. Mol Cell Biol. 1998;18(3):1517-24. [PubMed: 9488468]. [PubMed Central: PMC108866].

86. Eustace BK, Sakurai T, Stewart JK, Yimlamai D, Unger C, Zehetmeier $\mathrm{C}$, et al. Functional proteomic screens reveal an essential extracellular role for hsp90 alpha in cancer cell invasiveness. Nat Cell Biol. 2004;6(6):507-14. doi: 10.1038/ncb1131. [PubMed: 15146192].

87. Roe SM, Prodromou C, O'Brien R, Ladbury JE, Piper PW, Pearl LH. Structural basis for inhibition of the Hsp90 molecular chaperone by the antitumor antibiotics radicicol and geldanamycin. J Med Chem. 
1999;42(2):260-6. doi: 10.1021/jm980403y. [PubMed: 9925731].

88. Xu W, Marcu M, Yuan X, Mimnaugh E, Patterson C, Neckers L. Chaperone-dependent E3 ubiquitin ligase CHIP mediates a degradative pathway for c-ErbB2/Neu. Proc Natl Acad Sci U S A. 2002;99(20):12847-52. doi: 10.1073/pnas.202365899. [PubMed: 12239347]. [PubMed Central: PMC130548].

89. Castagnola P, Bellese G, Birocchi F, Gagliani MC, Tacchetti C, Cortese
K. Identification of an HSP90 modulated multi-step process for ERBB2 degradation in breast cancer cells. Oncotarget. 2016;7(51):85411-29. doi: 10.18632/oncotarget.13392. [PubMed: 27863425]. [PubMed Central: PMC5356745].

90. Morimoto RI, Santoro MG. Stress-inducible responses and heat shock proteins: New pharmacologic targets for cytoprotection. Nat Biotechnol.1998;16(9):833-8. doi:10.1038/nbt0998-833. [PubMed: 9743115]. 